\title{
The effects of trans-fatty acids on TAG regulation in mice depend on dietary unsaturated fatty acids
}

\author{
Juliana Saín ${ }^{1,2}$, Marcela Aída González ${ }^{1}$, Jimena Verónica Lavandera ${ }^{1,2}$, María Victoria Scalerandi ${ }^{1}$ and \\ Claudio Adrián Bernal ${ }^{1,2 *}$ \\ ${ }^{1}$ Cátedra de Bromatología y Nutrición, Facultad de Bioquímica y Ciencias Biológicas, Universidad Nacional del Litoral, \\ Ciudad Universitaria, Paraje el Pozo S/N, C.C. 242, C.P. 3000, Santa Fe, Argentina \\ ${ }^{2}$ Consejo Nacional de Investigaciones Científicas y Técnicas (CONICET), Colectora Ruta Nacional 168 Km O, "Predio CONICET \\ Dr. Alberto Cassano", C.P. 3000, Santa Fe, Argentina
}

(Submitted 2 February 2016 - Final revision received 5 April 2016 - Accepted 20 May 2016 - First published online 13 June 2016)

\section{Abstract}

The aim of this study was to investigate the effects of trans-fatty acids (TFA) on liver and serum TAG regulation in mice fed diets containing different proportions of $n-3, n-6$ and $n-9$ unsaturated fatty acids (UFA) from olive (O), maize (C) or rapeseed (R) oils partially substituted or not with TFA (Ot, Ct and Rt, respectively). Male CF1 mice were fed $(30 \mathrm{~d})$ one of these diets. The effects of the partial substitution $(1 \%$, w/w) of different UFA with TFA on the activity and expression of hepatic enzymes involved in lipogenesis and fatty acids oxidation were evaluated, as well as their transcription factor expressions. Some of the mechanisms involved in the serum TAG regulation, hepatic VLDL rich in TAG (VLDL-TAG) secretion rate and lipoprotein lipase (LPL) activity were assessed. In liver, TFA induced an increase in TAG content in the Ot and Rt groups, and this effect was associated with an imbalance between lipogenesis and $\beta$-oxidation. In the Ot group, exacerbated lipogenesis may be one of the mechanisms responsible for the liver steatosis induced by TFA, whereas in Rt it has been related to a decreased $\beta$-oxidation, compared with their respective controls. The enhanced hepatic VLDL-TAG secretion in the Ot and Rt groups was compensated with a differential removal of TAG by LPL enzyme in extrahepatic tissues, leading to unchanged serum TAG levels. In brief, the effects of low levels of TFA on liver and serum TAG regulation in mice depend on the dietary proportions of $n-3, n-6$ and $n-9$ UFA.

\section{Key words: Dietary fat: TAG metabolism: Lipogenesis: $\beta$-Oxidation: Lipoprotein lipase}

Fatty acids (FA) are strong modulators of a number of cell functions and regulate the potential risk and/or prevention of chronic diseases. The benefits of increasing the consumption of $n$ - 3 long-chain PUFA (LC-PUFA) and decreasing the intake of SFA are well known. However, the role of the proportions of dietary unsaturated fatty acids (UFA) on lipid metabolism is an attractive, although not very well-known, issue. There are many possible mechanisms involved in lipid regulation by UFA. For example, FA regulate the functionality of cell membranes, modify the plasma and tissue FA composition ${ }^{(1)}$ and bind to and modulate nuclear receptors that regulate genes related to lipid metabolism $^{(2-4)}$. Therefore, FA can modulate enzymes involved in de novo lipogenesis and MUFA synthesis, as well as plasma and tissue lipid content. Moreover, the balance of the dietary FA, and more specifically the $n-6: n-3$ PUFA ratio, can be crucial to prevent inflammatory processes, which could mediate some non-communicable chronic diseases ${ }^{(4-6)}$.
On the other hand, a high intake of industrial trans-fatty acids (TFA), mainly rich in trans-elaidic acid, has a negative impact on human health $^{(7)}$. The chronic consumption of industrial TFA has been associated with alterations in blood lipids, endothelial dysfunction, risk of $\mathrm{CVD}^{(8,9)}$ and increased incidence of different types of cancer ${ }^{(10-12)}$. TFA have shown to be incorporated into many tissues in both humans ${ }^{(13)}$ and experimental animal models ${ }^{(14,15)}$. We have recently published that, even at low intake levels of TFA, they are incorporated into the tissues and their retention is related to the UFA proportion of the diet ${ }^{(16)}$. In addition, we have demonstrated that the different biological effects of TFA are associated with the incorporation and retention of TFA into the tissues, the metabolic fate, the TFA bioconversion and the biosynthesis of LC-PUFA derivates, as well as with the alteration of the FA metabolic pathways. However, little is known about the effects of TFA on TAG levels in liver or skeletal muscle ${ }^{(17,18)}$ in animals fed diets containing

Abbreviations: ACC, acetyl-CoA carboxylase; C, maize oil-fed group; CPT-Ia, carnitine palmitoyltransferase-Ia; Ct, maize oil + TFA-fed group; EWAT, epididymal white adipose tissue; FA, fatty acids; FAS, fatty acid synthase; GM, gastrocnemius muscle; LA, linoleic acid; LPL, lipoprotein lipase; O, olive oil-fed group; OA, oleic acid; Ot, olive oil + TFA-fed group; R, rapeseed oil-fed group; Rt, rapeseed oil + TFA-fed group; SREBP, sterol regulatory element-binding protein; TFA; trans-fatty acids; UFA, unsaturated fatty acids; VLDL-TAG, VLDL rich in TAG.

* Corresponding author: Professor C. A. Bernal, fax +54 342457 5221, email cbernal@fbcb.unl.edu.ar 
different UFA proportions. Thus, the aim of the present study was to investigate the effects of TFA from partially hydrogenated vegetable oil on liver and serum TAG regulation in mice fed experimental diets rich in edible oils containing different UFA proportions. Therefore, the effects of both dietary variables on the activity and expression of hepatic enzymes involved in lipogenesis and FA oxidation, as well as their transcription factor expressions, were also assessed. In order to clarify some of the mechanisms involved in the serum TAG levels, we also assessed the VLDL rich in TAG (VLDL-TAG) secretion rate from the liver, and epididymal white adipose tissue (EWAT) and gastrocnemius muscle (GM) lipoprotein lipase (LPL) activity.

\section{Methods}

\section{Animals, diet preparation and experimental design}

The experiment was conducted with two sets of thirty-six male CF1 mice (six mice per group) at 2 weeks after weaning (22 g), provided from the facilities at our University according to the regulations of the School of Biochemistry, Guide to the Care and Use of Experimental Animals of Laboratory ${ }^{(19)}$. The animals were kept under controlled conditions $\left(23 \pm 2^{\circ} \mathrm{C}\right.$ and $12 \mathrm{~h}$ light$12 \mathrm{~h}$ dark cycle), and they had free access to food and water. Each set of mice was randomly divided into six groups of six animals each fed on experimental diets for $30 \mathrm{~d}$, differing in the source of fat: group $\mathrm{O}$ was fed a diet containing olive oil, group $\mathrm{C}$ was fed a diet containing maize oil, group $\mathrm{R}$ was fed a diet containing rapeseed oil. Groups Ot, Ct and Rt were fed an $\mathrm{O}, \mathrm{C}$ or R diet, respectively, partially substituted with partially hydrogenated vegetable oil. The FA composition of dietary fats was determined by GC, as shown in Table 1. The partially hydrogenated vegetable oil contained a mixture with three main TFA isomers: trans-9, trans-10 and trans-11-18:1. O, C and $\mathrm{R}$ oils provided oleic acid (OA), linoleic acid (LA) and $\alpha$-linoleic acid (ALA) in the proportions of (OA/LA/ALA) $55 \cdot 2 / 17 \cdot 2 / 0 \cdot 7 ; 32 \cdot 0 / 51 \cdot 3 / 0 \cdot 9$ and $61 \cdot 1 / 18 \cdot 4 / 8 \cdot 6$, respectively. The experimental diets were freshly prepared every $3 \mathrm{~d}$, gassed with $\mathrm{N}_{2}$ and stored at $0-4^{\circ} \mathrm{C}$. The diet composition is shown in Table 2 , and it provided $64.4 \%$ of dietary energy as carbohydrates and $19.9 \%$ of dietary energy as protein. O, C and R diets contained $15.7 \%$ of dietary energy as total fat, whereas Ot, Ct and Rt contained $15.7 \%$ of dietary energy as total fat, of which $1.5 \%$ of energy as TFA.

The partially hydrogenated vegetable oil was kindly provided by Compañía Argentina de Levaduras S.A. Olive oil, maize oil, rapeseed oil, sucrose, cellulose, casein and maize starch were obtained from local sources. Vitamin and mineral mixes were formulated according to the AIN-93G guidelines ${ }^{(20)}$ using compounds of food grade or better. Cysteine, methionine and choline were purchased from Sigma.

\section{Extraction of tissues and serum samples}

After $30 \mathrm{~d}$ of dietary treatment, one set of animals ( $n$ 36) was fasted overnight, anaesthetised and killed (09.00-11.00 hours) under anaesthesia ( $1 \mathrm{mg}$ azepromazine $+100 \mathrm{mg}$ ketamine $/ \mathrm{kg}$ body weight) by cardiac exsanguination. Blood was collected and serum was obtained after centrifugation (1000 $\boldsymbol{g}$ for $10 \mathrm{~min}$ at $4^{\circ} \mathrm{C}$ ). Liver, GM and EWAT were dissected, weighed and immediately frozen. All samples were stored at $-80^{\circ} \mathrm{C}$ until analysis.

Table 1. Fatty acid composition of the experimental diets (\% of total fatty acids methyl esters)

\begin{tabular}{|c|c|c|c|c|c|c|}
\hline \multirow[b]{2}{*}{ Fatty acid } & \multicolumn{6}{|c|}{ Diets } \\
\hline & $\mathrm{O}$ & $\mathrm{C}$ & $\mathrm{R}$ & Ot & $\mathrm{Ct}$ & Rt \\
\hline $14: 0$ & ND & 0.0 & 0.1 & ND & ND & ND \\
\hline $16: 0$ & $17 \cdot 1$ & $12 \cdot 2$ & 4.0 & $16 \cdot 4$ & 11.8 & $6 \cdot 1$ \\
\hline $17: 0$ & 0.1 & ND & ND & ND & 0.1 & ND \\
\hline $18: 0$ & 1.6 & 1.9 & $2 \cdot 2$ & 4.5 & 4.5 & 4.5 \\
\hline $20: 0$ & 0.3 & 0.5 & 0.5 & 0.4 & 0.4 & 0.5 \\
\hline $22: 0$ & 0.1 & 0.2 & 0.2 & 0.2 & 0.2 & 0.3 \\
\hline cis-9-16: 1 & $2 \cdot 0$ & 0.1 & 0.2 & 1.7 & 0.1 & 0.1 \\
\hline cis-6-18:1 & ND & ND & ND & 1.90 & 1.79 & 2.04 \\
\hline cis-9-18: 1 & $55 \cdot 2$ & 31.9 & $61 \cdot 1$ & $47 \cdot 2$ & 29.0 & 51.5 \\
\hline cis-11-18: 1 & 4.8 & 0.5 & 3.5 & 3.7 & 1.3 & 3.3 \\
\hline cis-11-20:1 & 0.2 & 0.2 & 0.9 & 0.2 & 0.2 & 0.7 \\
\hline$($ trans $-6+$ trans $-7+$ trans -8$)-18: 1$ & ND & ND & ND & 1.6 & 1.6 & 1.6 \\
\hline trans-9-18: 1 & ND & ND & ND & $2 \cdot 2$ & $2 \cdot 4$ & $2 \cdot 1$ \\
\hline trans-10-18:1 & ND & ND & ND & 2.7 & 3.1 & 3.0 \\
\hline trans-11-18: 1 & ND & ND & ND & 2.5 & 2.5 & $2 \cdot 6$ \\
\hline cis-9,cis-12-18:2 & $17 \cdot 2$ & 51.3 & 18.4 & 11.7 & 38.4 & $13 \cdot 3$ \\
\hline cis-9, cis-12, cis-15-18:3 & 0.7 & 0.9 & 8.6 & 0.6 & 0.7 & $6 \cdot 2$ \\
\hline cis-5,cis-8, cis-11,cis-14-20:4 & 0.2 & ND & ND & 0.4 & ND & ND \\
\hline $\begin{array}{l}\text { cis- } 5 \text {, cis- } 8 \text {, cis- } 11 \text {, cis- } 14 \\
\text { cis- } 17-20: 5\end{array}$ & ND & 0.1 & ND & ND & 0.2 & ND \\
\hline trans -9, trans $-12-18: 2$ & ND & ND & ND & 0.3 & 0.3 & 0.3 \\
\hline Unidentified & 0.5 & ND & 0.2 & 1.8 & 1.6 & 1.8 \\
\hline
\end{tabular}

O, olive oil diet; C, maize oil diet; R, rapeseed oil diet; Ot, olive oil diet supplemented with trans-fatty acids; Ct, maize oil diet supplemented with trans-fatty acids; Rt, rapeseed oil diet supplemented with trans-fatty acids; ND, not detected. 
Table 2. Composition of the experimental diets ( $\mathrm{g} / \mathrm{kg}$ dry diet)

\begin{tabular}{|c|c|c|c|c|c|c|}
\hline & \multicolumn{6}{|c|}{ Diets } \\
\hline & O & $\mathrm{C}$ & $\mathrm{R}$ & Ot & $\mathrm{Ct}$ & Rt \\
\hline Olive oil & $70 \cdot 0$ & - & - & $50 \cdot 0$ & - & - \\
\hline Maize oil & - & $70 \cdot 0$ & - & - & $50 \cdot 0$ & - \\
\hline Rapeseed oil & - & - & $70 \cdot 0$ & - & - & $50 \cdot 0$ \\
\hline Partially hydrogenated vegetable oil & - & - & - & $20 \cdot 0$ & $20 \cdot 0$ & $20 \cdot 0$ \\
\hline Casein & $200 \cdot 0$ & $200 \cdot 0$ & $200 \cdot 0$ & $200 \cdot 0$ & $200 \cdot 0$ & $200 \cdot 0$ \\
\hline Starch & $529 \cdot 0$ & $529 \cdot 0$ & 529.0 & 529.0 & $529 \cdot 0$ & $529 \cdot 0$ \\
\hline Sucrose & $100 \cdot 0$ & $100 \cdot 0$ & $100 \cdot 0$ & $100 \cdot 0$ & $100 \cdot 0$ & $100 \cdot 0$ \\
\hline Cellulose & $50 \cdot 0$ & $50 \cdot 0$ & $50 \cdot 0$ & $50 \cdot 0$ & $50 \cdot 0$ & $50 \cdot 0$ \\
\hline Vitamin mix & $10 \cdot 0$ & $10 \cdot 0$ & $10 \cdot 0$ & $10 \cdot 0$ & $10 \cdot 0$ & $10 \cdot 0$ \\
\hline Mineral mix & $35 \cdot 0$ & $35 \cdot 0$ & $35 \cdot 0$ & $35 \cdot 0$ & $35 \cdot 0$ & $35 \cdot 0$ \\
\hline Cys/Met/choline & 5.5 & 5.5 & 5.5 & 5.5 & 5.5 & 5.5 \\
\hline Energy $(\mathrm{kJ} / \mathrm{g})$ & $14 \cdot 8$ & 14.8 & $14 \cdot 8$ & 14.8 & $14 \cdot 8$ & 14.8 \\
\hline
\end{tabular}

O, olive oil diet; C, maize oil diet; R, rapeseed oil diet; Ot, olive oil diet supplemented with trans-fatty acids; Ct, maize oil diet supplemented with trans-fatty acids; Rt, rapeseed oil diet supplemented with trans-fatty acids.

* Partially hydrogenated vegetable oil contains about $42 \%$ of trans-fatty acids.

\section{Determination of TAG content in serum and tissues}

Serum TAG levels were determined by spectrophotometry using a commercial kit (Wiener Lab).

To assess the liver and GM TAG content, portions of frozen tissue $(0.5 \mathrm{~g})$ were powdered and homogenised in saline $(10 \%$, $\mathrm{w} / \mathrm{v}$ ) for TAG content quantification. Tissue TAG levels were determined by the method of Laurell ${ }^{(21)}$. In brief, approximately $200 \mathrm{mg}$ of frozen tissue were homogenised in saline solution 1:10 with a homogeniser and sonicated for $30 \mathrm{~s}$. Complete cell destruction was achieved by one freeze-thaw cycle and two $15 \mathrm{~s}$ cycles of sonication (amplitude: $10 \mu \mathrm{m}$ ). TAG content was analysed using the same protocol cited by Laurell.

\section{Liver enzyme activities}

Liver samples $(1.0 \mathrm{~g})$ were homogenised in $2.5 \mathrm{ml}$ of buffer (pH 7.6) containing $150 \mathrm{~mm}-\mathrm{KCl}, 1 \mathrm{~mm}-\mathrm{MgCl}_{2}, 10 \mathrm{~mm}-\mathrm{N}$-acetylcysteine and $0.5 \mathrm{~mm}$-dithiothreitol. After centrifugation at $100000 \mathbf{g}$ for $40 \mathrm{~min}$ at $4^{\circ} \mathrm{C}$, the supernatant fraction was used for quantification of enzyme activities. Acetyl-CoA carboxylase (ACC, EC 6.4.1.2), fatty acid synthase (FAS, EC 2.3.1.85), glucose-6 phosphate dehydrogenase (G6PDH, EC 1.1.1.49) and malic enzyme (ME, EC 1.1.1.40) activities were measured following a previously used protocol ${ }^{(22)}$. Enzyme activities were expressed either as nmol NADH consumed (ACC), as nmol NADPH consumed (FAS) or as nmol NADPH produced (G6PDH and ME), per min and per mg of protein. Protein content was determined using bovine serum albumin as standard ${ }^{(23)}$.

Carnitine palmitoyltransferase-Ia (CPT-Ia, EC 1.3.99.3) activity was assessed in the mitochondrial fraction. Liver samples $(0.5 \mathrm{~g})$ were homogenised in $3 \mathrm{vol}(\mathrm{w} / \mathrm{v})$ of buffer $\mathrm{pH} 7 \cdot 4$ containing $0.25 \mathrm{~mol} / 1$ sucrose, $1 \mathrm{mmol} / 1$ EDTA and $10 \mathrm{mmol} / 1 \mathrm{Tris}-\mathrm{HCl}$. Homogenates were centrifuged $\left(700 \boldsymbol{g}\right.$ for $10 \mathrm{~min}$ at $4^{\circ} \mathrm{C}$ ) and supernatant fluid was again centrifuged $(12000 \boldsymbol{g}$ for $15 \mathrm{~min}$ at $4^{\circ} \mathrm{C}$ ). Pellets were resuspended in $70 \mathrm{mmol} / \mathrm{l}$ sucrose, $220 \mathrm{mmol} / 1 \mathrm{mannitol}, 1 \mathrm{mmol} / \mathrm{l}$ EDTA and $2 \mathrm{mmol} / \mathrm{l}$ HEPES buffer at $\mathrm{pH} 7 \cdot 4$. CPT-Ia activity was assayed by means of the Bieber method ${ }^{(24)}$. The pellet protein content was determined as described above. CPT-Ia activity was expressed as nmol CoA formed/min per mg protein.

The removal capability of TAG-rich lipoproteins was evaluated by LPL activity in the main tissues responsible for the uptake of TAG: adipose tissue and muscle. The LPL enzyme activity was measured using a fluorimetric method based on Del Prado et $a l .{ }^{(25)}$. Basically, the dibutyryl fluorescein was used as substrate for the enzyme, and the fluorescein liberated by enzymatic hydrolysis of the substrate was measured. Dibutyryl fluorescein was synthesised as described by Kramer \& Guilbault ${ }^{(26)}$.

The enzymatic activity of adipose tissue LPL was quantified in EWAT acetone powder. In brief, EWAT samples were delipidated by a double extraction with cold acetone followed by a double extraction with diethyl ether. The powders obtained

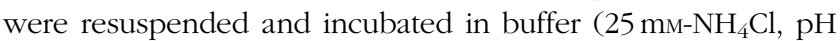
$8 \cdot 1$ containing $1 \mathrm{IU} / \mathrm{ml}$ of heparin). The enzymatic reaction was carried out in a medium containing dibutyryl fluorescein as enzyme substrate. The quantification of LPL activity was performed by measuring the increase in fluorescence ( $\lambda$ excitation $=490 \mathrm{~nm} ; \lambda$ emission $=530 \mathrm{~nm}$ ). In parallel, an identical assay was carried out in the same samples but in the presence of $\mathrm{NaCl}$ during incubation to inhibit specific enzyme activity. LPL activity was estimated as the difference between the total lipolitic and the non-specific lipolitic activity. Values were expressed as $\mu \mathrm{mol}$ fluorescein/min per g of tissue and as $\mu \mathrm{mol}$ fluorescein/min per total tissue.

To assess muscle LPL activity, GM samples were homogenised in $\mathrm{NH}_{4} \mathrm{Cl} / \mathrm{NH}_{4} \mathrm{OH}$ - heparin buffer. Then, the quantification of LPL activity in GM was performed as previously described for EWAT without the step of delipidation. The measured activity was expressed as $\mu \mathrm{mol}$ fluorescein/min per total muscle.

\section{Extraction and analysis of MRNA and quantification by real-time $P C R$}

Total RNA was isolated from $100 \mathrm{mg}$ of liver using Trizol (Invitrogen), according to the manufacturer's instructions. RNA samples were then treated with a DNA-free kit (Applied 
Biosystems) to remove any contamination with genomic DNA. The yield and quality of the RNA were assessed by measuring absorbance at 260, 270, 280 and $310 \mathrm{~nm}$ and by electrophoresis on $1.3 \%$ agarose gels. A quantity of $1.5 \mu \mathrm{g}$ of total RNA of each sample was reverse-transcribed to first-strand complementary DNA (cDNA) using an iScript ${ }^{\mathrm{TM}}$ cDNA Synthesis Kit (Bio-Rad).

Relative ACC, FAS, sterol regulatory element-binding protein (SREBP)-1a, SREBP-1c, CPT-Ia and PPAR- $\alpha$ mRNA levels were quantified using real-time PCR with an iCycler ${ }^{\mathrm{TM}}-\mathrm{MyiQ}^{\mathrm{TM}}$ RealTime PCR Detection System (Bio-Rad). $\beta$-Actin mRNA levels were similarly measured and served as the reference gene. A quantity of $0 \cdot 1 \mu \mathrm{l}$ of each cDNA was added to a PCR reagent mixture, SYBR ${ }^{\circledR}$ Green Master Mix (Applied Biosystems), with the upstream and downstream primers (300 nм for SREBP-1a, $600 \mathrm{~nm}$ for FAS and ACC and $900 \mathrm{~nm}$ for CPT-Ia, SREBP-1c and PPAR- $\alpha$ ). Specific primers were designed (Genbank: NM_133360 ACC; NM-007988 FAS; NM_011480 SREBP-1a and SREBP-1c; NM-031559 CPT-Ia; AJ312092 $\beta$-actin; NM_011144.6 PPAR- $\alpha$ ) and commercially synthesised (TIB Molbiol), and the sequences were as follows:

ACC: 5'-GGA CCA CTG CAT GGA ATG TTA A-3' (forward); 5'-TGA GTG ACT GCC GAA ACA TCT C-3' (reverse).

FAS: 5'-AGC CCC TCA AGT GCA CAG TG-3' (forward); 5'-TGC CAA TGT GTT TTC CCT GA-3' (reverse).

SREBP-1a: 5'-GGC TGT GGA ACA GGC ACT G-3' (forward);

5'-AGC TGG AGC ATG TCT TCG ATG-3' (reverse).

SREBP-1C: 5'-GCG GAC GCA GTC TGG G-3' (forward); 5'-ATG AGC TGG AGC ATG TCT TCA AA-3' (reverse).

CPT-Ia: 5'-GCA GAG GAC GGG CAT TGT A-3' (forward); 5'TGT AGC CTG GTG GGT TTG G-3' (reverse).

PPAR- $\alpha$ : 5'-CTC TTT CGT TTT GAC TTT CGT CTC T-3' (forward); 5'-GAA GGG CGG GTT ATT GCT G-3' (reverse).

The PCR parameters were as follows: initial $2 \mathrm{~min}$ at $50^{\circ} \mathrm{C}$, denaturation at $95^{\circ} \mathrm{C}$ for $10 \mathrm{~min}$ followed by forty cycles of denaturation at $95^{\circ} \mathrm{C}$ for $15 \mathrm{~s}$ and combined annealing and extension at $60^{\circ} \mathrm{C}$ for $1 \mathrm{~min}$. All sample mRNA levels were normalised to the values of $\beta$-actin, and the results were expressed as fold changes of threshold cycle $\left(C_{t}\right)$ value relative to controls using the $2^{-\Delta \Delta C_{t}} \operatorname{method}^{(27)}$.

\section{Estimation of 'in vivo' VLDL-TAG secretion rate}

Another set of animals ( $n$ 36) submitted to the same dietary treatment was fasted overnight, and anaesthetised as indicated above. Then, $600 \mathrm{mg} / \mathrm{kg}$ of body weight of Triton WR 1339 (Sigma-Aldrich) in saline solution, an agent known to inhibit the peripheral removal of TAG-rich lipoproteins, was injected intravenously ${ }^{(28)}$. Blood samples were taken immediately before and $120 \mathrm{~min}$ after the injection of Triton solutions for estimation of TAG accumulation. The VLDL-TAG secretion rate was estimated based on plasma TAG concentrations at 0 and $120 \mathrm{~min}$, plasma volume and body weight. Further details have been previously reported ${ }^{(29)}$.

\section{Statistical analysis}

The statistical analysis was performed using SPSS 17.0 (SPSS Inc.). Values were expressed as means with their standard errors, and were statistically analysed by $2 \times 3$ ANOVA. All post hoc multiple comparisons were made using Tukey's critical range test. For the mRNA statistical analysis, Student's $t$ test was performed comparing $\Delta \Delta C_{t}$ between pairs of groups. Significant differences were considered at $P<0.05$ for both analyses.

\section{Results}

Tissues weights, liver, muscle and serum TAG levels, VLDLTAG secretion rate and lipoprotein lipase activities

Results concerning tissue weights, liver and GM TAG content and serum TAG levels, as well as TAG secretion rate and LPL activities, are shown in Table 3. No significant differences were observed in liver, GM and EWAT weights either in animals fed $\mathrm{O}, \mathrm{C}, \mathrm{R}$ diets or in animals fed diets containing TFA $v$. their respective controls. The partial substitution with TFA to diets increased the TAG content in liver of Ot and Rt compared with $\mathrm{O}$ and $\mathrm{R}$ groups, respectively. In GM, no significant differences were observed in the TAG content in the groups fed $\mathrm{O}, \mathrm{C}$ and $\mathrm{R}$ diets. However, dietary TFA decreased this parameter in the Ot group with respect to $\mathrm{O}$. On the other hand, serum TAG levels were dependent on the source of fat $(P<0 \cdot 001)$. Specifically, animals fed diets containing rapeseed oil showed the highest TAG levels, independently of the presence of dietary TFA.

The in vivo VLDL-TAG secretion rate was increased in the Ot and Rt groups compared with their respective controls and also the VLDL-TAG secretion rate was Ot>Rt, showing different effect of TFA depending the source of fat. No significant differences were observed in LPL activity in EWAT when it was expressed per $g$ of tissue between experimental groups. However, the contribution of this tissue to the total TAG removal rate was significantly lower in the $\mathrm{O}$ and $\mathrm{R}$ groups compared with $\mathrm{C}$, and the intake of diets containing TFA increased this parameter in the Ot and Rt groups compared with their respective controls. In GM, the LPL activity was lower in the R group, reaching significant differences $v$. O. The presence of TFA reduced this parameter when maize oil was the source of fat.

\section{Lipogenic and oxidative enzyme activities}

No significant differences were observed in the G6PDH, FAS and ACC activities between the animals fed O, C and R diets (Table 4). The partial substitution with TFA in the olive oil diet increased the activities of lipogenic enzymes, and the ACC activity was lower in Rt $v$. their respective control. In liver, the activity of CPT-Ia, an indicator of mitochondrial FA oxidation, was increased in $\mathrm{R}$ compared with the $\mathrm{O}$ and $\mathrm{C}$ groups. The presence of dietary TFA decreased this parameter only in the Rt group $v$. its respective control.

mRNA levels of enzymes and transcriptional factors in liver

The partial substitution with TFA increased the expression of Fas and Acc in animals fed the olive oil diet (Fig. 1(A) and (B)), 
as well as the Srebf1a (SREBP-1a gene) (Fig. 2(A)). No changes were observed in the expression of Srebf1c (SREBP-1c gene) (Fig. 2(B)). With regard to FA oxidation, the expression of Cpt1a in liver was higher in the $\mathrm{R}$ group and reduced by the presence of TFA (Fig. 1(C)). The expression of Ppara followed the same trend (Fig. 2(C)).

\section{Discussion}

To the best of our knowledge, this is the first study to investigate the potential effect of dietary TFA at different UFA proportions on liver and serum TAG regulation. Interestingly, in the present study, the partial substitution with TFA on diets containing different edible oils led to dissimilar effects on TAG metabolism. In liver, TFA induced an increase in TAG content in the Ot and Rt groups, and this effect was associated with an imbalance between lipogenesis and $\beta$-oxidation. Several studies have associated the accretion of hepatic lipids with changes in these parameters $^{(30-32)}$. As previously demonstrated ${ }^{(22)}$, in mice fed diets containing olive oil as a source of fat and partially substituted with TFA, the exacerbated lipogenesis may be one of the mechanisms responsible for the elevated liver TAG accretion induced by the presence of TFA. Specifically, the increased expression and activity of the lipogenic enzymes associated with the high mRNA levels of SREBP-1a led to an increase in liver TAG content in the Ot group with respect to $O$. In the present study, the raised hepatic TAG accretion observed in Rt has been related to a decreased $\beta$-oxidation, compared with the $\mathrm{R}$ group. Specifically, we observed an increased expression and activity of CPT-Ia in R compared with the $\mathrm{O}$ and $\mathrm{C}$ groups, associated with a greater expression of Ppara. The partial substitution with TFA reduced these parameters. In agreement with these findings, Pawar et al. ${ }^{(33)}$ reported that $n$-3 PUFA might activate the PPAR- $\alpha$ in rat primary hepatocytes, leading to a greater $\beta$-oxidation. Furthermore, Giudetti et $a l .{ }^{(34)}$ demonstrated that dietary TFA might affect the $\beta$-oxidation of FA reducing the CPT-1a activity in rat liver compared with diets without TFA. As regards the $\mathrm{C}$ and $\mathrm{Ct}$ groups, no alterations were observed in the expression and activities of enzymes involved in both lipogenesis and $\beta$-oxidation. Consequently, the lack of effects in the hepatic TAG content might be associated with the absence of changes in these parameters. As we have recently observed $^{(16)}$ that the total TFA retained in the Ot, Ct and Rt groups was similar, the differences in liver TAG content, hepatic lipogenesis and $\beta$-oxidation between these groups cannot be explained by the differences in the hepatic incorporation of TFA isomers. In a recent research article published by our group ${ }^{(16)}$, it was shown that the liver of mice from the $\mathrm{Ct}$ group contained a significantly higher percentage of LA and a lower percentage of OA than those from the Ot and Rt groups. It has been demonstrated that LA reduces liver lipogenesis in comparison with $\mathrm{OA}^{(35,36)}$. Thus, we could claim that the effect of TFA was mitigated by LA in the Ct group but not in the Ot and Rt groups. In contrast, several authors have observed that TFA increase the content of TAG in liver in diets containing maize oil ${ }^{(34,37-39)}$. In addition, compared with our results this discrepancy might be explained by differences in the 
Table 4. Liver enzyme activities ( $\mathrm{nmol} / \mathrm{min}$ per $\mathrm{mg}$ protein) (Mean values with their standard errors for six animals per group)

\begin{tabular}{|c|c|c|c|c|c|c|c|c|c|c|c|c|c|c|c|}
\hline & \multicolumn{2}{|c|}{$\mathrm{O}$} & \multicolumn{2}{|c|}{ Ot } & \multicolumn{2}{|c|}{ C } & \multicolumn{2}{|c|}{$\mathrm{Ct}$} & \multicolumn{2}{|c|}{$\mathrm{R}$} & \multicolumn{2}{|c|}{$\mathrm{Rt}$} & \multicolumn{3}{|c|}{$2 \times 3$ ANOVA $P^{*}$} \\
\hline & Mean & SEM & Mean & SEM & Mean & SEM & Mean & SEM & Mean & SEM & Mean & SEM & $\mathrm{F}$ & $\mathrm{t}$ & $F \times t$ \\
\hline FAS & $18 \cdot 1^{a}$ & 0.7 & $51 \cdot 7^{\mathrm{C}}$ & $7 \cdot 3$ & $31 \cdot 0^{a, b}$ & $3 \cdot 3$ & $21 \cdot 7^{\mathrm{a}}$ & 1.8 & $33 \cdot 3^{a, b}$ & $2 \cdot 9$ & $41 \cdot 8^{\mathrm{b}, \mathrm{c}}$ & 4.8 & 0.028 & 0.003 & 0.000 \\
\hline ME & $85 \cdot 1^{a, b}$ & $2 \cdot 4$ & $118 \cdot 4^{c}$ & $6 \cdot 8$ & $67 \cdot 9^{\mathrm{a}, \mathrm{d}}$ & $5 \cdot 6$ & $61 \cdot 7^{d}$ & $2 \cdot 4$ & $97 \cdot 4^{\mathrm{b}, \mathrm{c}}$ & $4 \cdot 8$ & $86 \cdot 3^{a, b}$ & $4 \cdot 8$ & 0.000 & 0.371 & 0.000 \\
\hline ACC & $28 \cdot 1^{\mathrm{a}}$ & 1.7 & $39.1^{\mathrm{b}}$ & $1 \cdot 1$ & $30 \cdot 3^{\mathrm{a}}$ & $2 \cdot 8$ & $39 \cdot 3^{a, b}$ & 3.7 & $35 \cdot 4^{\mathrm{a}}$ & 5.0 & $16 \cdot 4^{\mathrm{c}}$ & $2 \cdot 6$ & 0.010 & 0.870 & 0.000 \\
\hline G6PDH & $18 \cdot 8^{a}$ & $2 \cdot 2$ & $34.5^{\mathrm{b}}$ & $2 \cdot 2$ & $16 \cdot 1^{\mathrm{a}}$ & $2 \cdot 5$ & $20 \cdot 2^{a}$ & 0.5 & $21 \cdot 1^{a}$ & $1 \cdot 2$ & $16 \cdot 8^{\mathrm{a}}$ & 1.0 & 0.000 & 0.035 & 0.508 \\
\hline CPT-Ia & $2 \cdot 8^{a}$ & 0.6 & $3.8^{\mathrm{a}}$ & 0.9 & $2 \cdot 2^{\mathrm{a}}$ & 0.3 & $3 \cdot 6^{a}$ & 0.9 & $6 \cdot 7^{b}$ & 0.2 & $2 \cdot 3^{a}$ & 0.7 & 0.947 & 0.592 & 0.000 \\
\hline
\end{tabular}

O, olive oil diet; TFA, trans-fatty acids; Ot, olive oil diet supplemented with TFA; C, maize oil diet; Ct, maize oil diet supplemented with TFA; R, rapeseed oil diet; Rt, rapeseed oil diet supplemented with TFA; FAS, fatty acid synthase; ME, malic enzyme; ACC, acetyl-CoA carboxylase; G6PDH, glucose-6 phosphate dehydrogenase; CPT-la, carnitine palmitoyltransferase-la.

a,b,c,d Mean values within a row with unlike superscript letters were significantly different $(P<0.05)$.

${ }^{*} \mathrm{~F}, \mathrm{t}$ and $\mathrm{F} \times \mathrm{t}$ correspond to $P$ values of $2 \times 3$ ANOVA to the effect of fat, TFA and interaction of fat $\times$ TFA.

experimental design: levels of dietary fat $(7,10,12,20 \%)$, high content of TFA and the type of FA isomers, among others. Particularly, the fat used in the present study contains equimolecular levels of vaccenic and elaidic acid, and dissimilar and/or opposite biological effects have been reported between both isomeric TFA ${ }^{(40-42)}$. Therefore, it cannot be excluded that there might exist a counteracting effect of vaccenic acid on elaidic acid attenuating the alterations induced by the TFA.

Changes in the hepatic TAG content are regulated by a number of mechanisms including TAG synthesis and VLDLTAG assembly and secretion to plasma, among others. Several authors $^{(43-46)}$ have studied, both in vivo and in vitro, the secretion of VLDL-TAG-rich particles from the liver, showing a link between the liver TAG pool and/or the apo synthesis. In the present study, the high levels of the hepatic TAG in the Ot and Rt groups were correlated to a greater VLDL-TAG secretion. This suggests that, under our experimental conditions, the TFA regulating the hepatic TAG accretion promote the TAG secretion in VLDL particles. In addition, we cannot preclude that the increased VLDL-TAG secretion rate could be associated with an enhanced apo-B synthesis. In this matter, Arrol et al. ${ }^{(44)}$ demonstrated that a high TAG content in isolated hepatocytes increased the apo-B secretion to the medium. On the other hand, Mitmesser \& Carr ${ }^{(46)}$ demonstrated that, compared with OA, elaidic acid increased the apo-B secretion in Hep-G2 cells. In the same way, rumenic acid $(c 9, t 11-18: 2)$ also showed the same effect in comparison with LA, and this indicates that transisomers could enhance the apo-B secretion more than their cis counterpart. In contrast, Dashti et al. ${ }^{(43,45)}$ demonstrated that elaidic acid did not increase the apo-B secretion compared with OA. Nevertheless, the authors reported that the different FA had more effects on VLDL composition than in the amount of lipoprotein secreted by hepatocytes.

Despite the increase in liver TAG in the Ot and Rt groups, and the consequent enhanced VLDL-TAG secretion, the serum TAG levels did not show greater levels in these groups. Instead, the effects found in serum TAG levels were associated with the source of UFA rather than with the presence of TFA. Specifically, serum TAG levels were increased in animals fed rapeseed oil, compared with the animals fed maize and olive oil diets, independently of TFA intake. These results do not seem to agree with the beneficial effects associated with the $n-3$ FA intake on serum lipids. Nevertheless, these effects have been attributed to the intake of $n-3$ LC-PUFA: EPA and $\mathrm{DHA}^{(30,32,47,48)}$. In this respect, in mice fed rapeseed oil it was observed that serum TAG levels were higher than in mice fed fish oil ${ }^{(32)}$. The authors claimed that dietary LC-PUFA might have different metabolic fates from those synthesised in vivo from ALA and thus could govern different regulatory pathways.

Previously, in our laboratory, it was shown that rats fed high levels of a trans-fat rich in elaidic acid showed increased levels of serum $\mathrm{TAG}^{(37,38)}$. However, in the present study, no hyperlipidaemic effects were found in animals fed diets containing TFA. This discrepancy might be explained by both the type of hydrogenated fat used and the experimental animal model used. The hydrogenated fat used had equivalent levels of three $t-18: 1$ isomers: vaccenic acid, elaidic acid and trans-10 18:1. According to our results, Tyburczy et al. ${ }^{(49)}$ demonstrated that hamsters fed diets rich in either vaccenic acid or elaidic acid and a diet containing a hydrogenated fat similar to the one used in this study did not show alterations in serum TAG, suggesting that other variables, different from the type of isomer, could be present.

It is widely known that, in fasting, serum TAG levels are related to the balance between the hepatic secretion and the peripheral tissue clearance through LPL activity. Therefore, the potential discrepancy observed between the high liver TAG secretion and the normal serum TAG levels could be explained by a differential removal of TAG by LPL enzyme in extrahepatic tissues. The adipose tissue is a key organ involved in the incorporation of TAG from the VLDL particles. In the absence of TFA, the $\mathrm{C}$ group showed a higher LPL activity than $\mathrm{O}$ and $\mathrm{R}$. These results are in agreement with those obtained by several authors ${ }^{(50-52)}$ who demonstrated that high levels of dietary UFA led to an increase in the LPL activity. Accordingly, the $\mathrm{C}$ diet had the highest levels of total PUFA, and this could explain the enhanced LPL activity in EWAT. The lower activity in the $\mathrm{R}$ group than in the $\mathrm{C}$ group suggests that one of the mechanisms responsible for the high levels of TAG in serum in the $\mathrm{R}$ group might be related to the lower LPL activity in comparison with the $\mathrm{C}$ group. However, several authors have demonstrated that animals fed rapeseed oil show greater levels of LPL activity in adipose tissue in comparison with other oils enriched in $n-3$ and $n-6$ PUFA $^{(53-55)}$. Among other reasons, the differences found with our results might be related to disparities between species, differences between in vitro and 
(A)

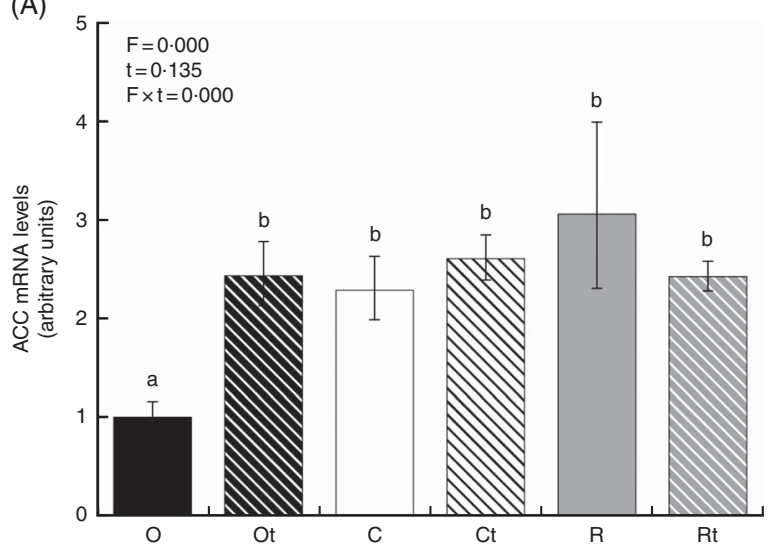

(B)
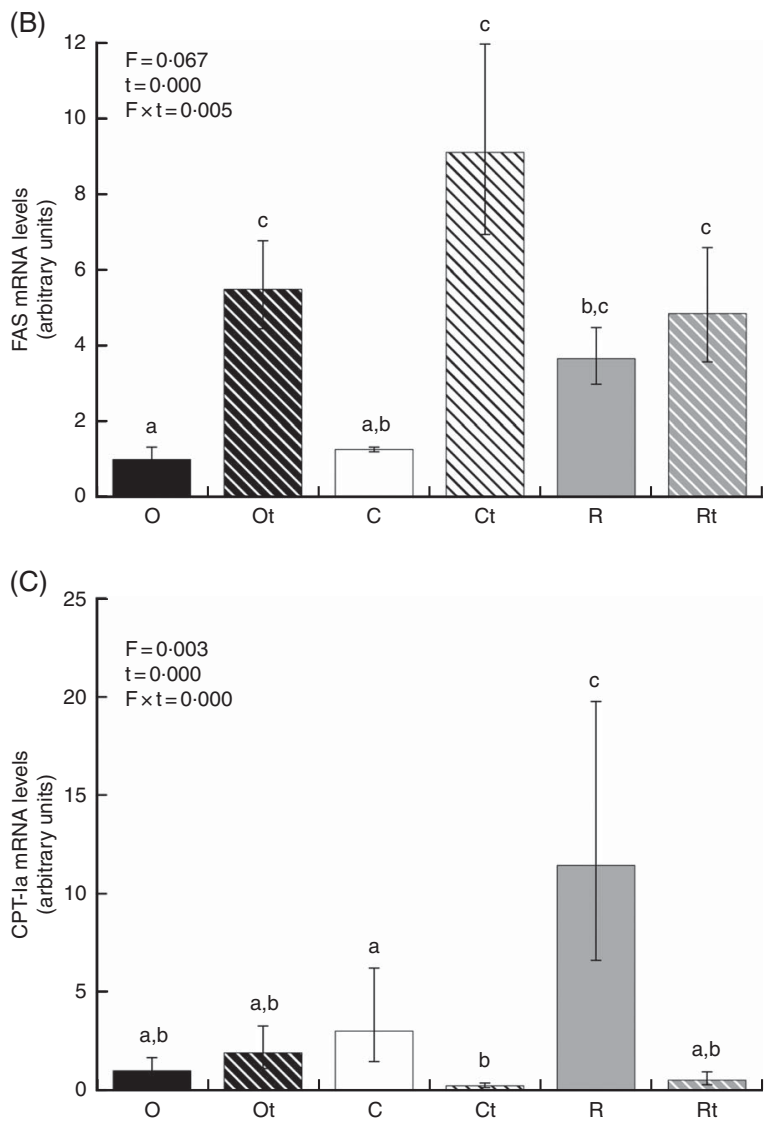

Fig. 1. Liver mRNA levels of key enzymes involved in lipogenesis and $\beta$-oxidation. $\mathrm{O}$, olive oil diet; Ot, olive oil diet supplemented with trans-fatty acids; C, maize oil diet; $\mathrm{Ct}$, maize oil diet supplemented with trans-fatty acids; $\mathrm{R}$, rapeseed oil diet; $\mathrm{Rt}$, rapeseed oil diet supplemented with trans-fatty acids; FAS, fatty acid synthase; ACC, acetyl-CoA carboxylase; CPT-la, carnitine palmitoyltransferase-la. Values are means (six animals per group), with their standard errors represented by vertical bars. ${ }^{a, b, c}$ Mean values with unlike letters were significantly different $(P<0.05) . \mathrm{F}, \mathrm{t}$ and $\mathrm{F} \times \mathrm{t}$ correspond to $P$ values of $2 \times 3$ ANOVA to the effect of fat, TFA and interaction of fat $\times$ TFA.

in vivo experiments, and/or age of the animals. The presence of TFA in the diets increased the EWAT LPL activity in a fat sourcedependent way. Thus, the animals fed Ot and Rt diets showed a higher LPL activity with respect to their controls. In contrast, other authors did not find ${ }^{(56,57)}$ or observe a low removal rate $e^{(58)}$ in rats
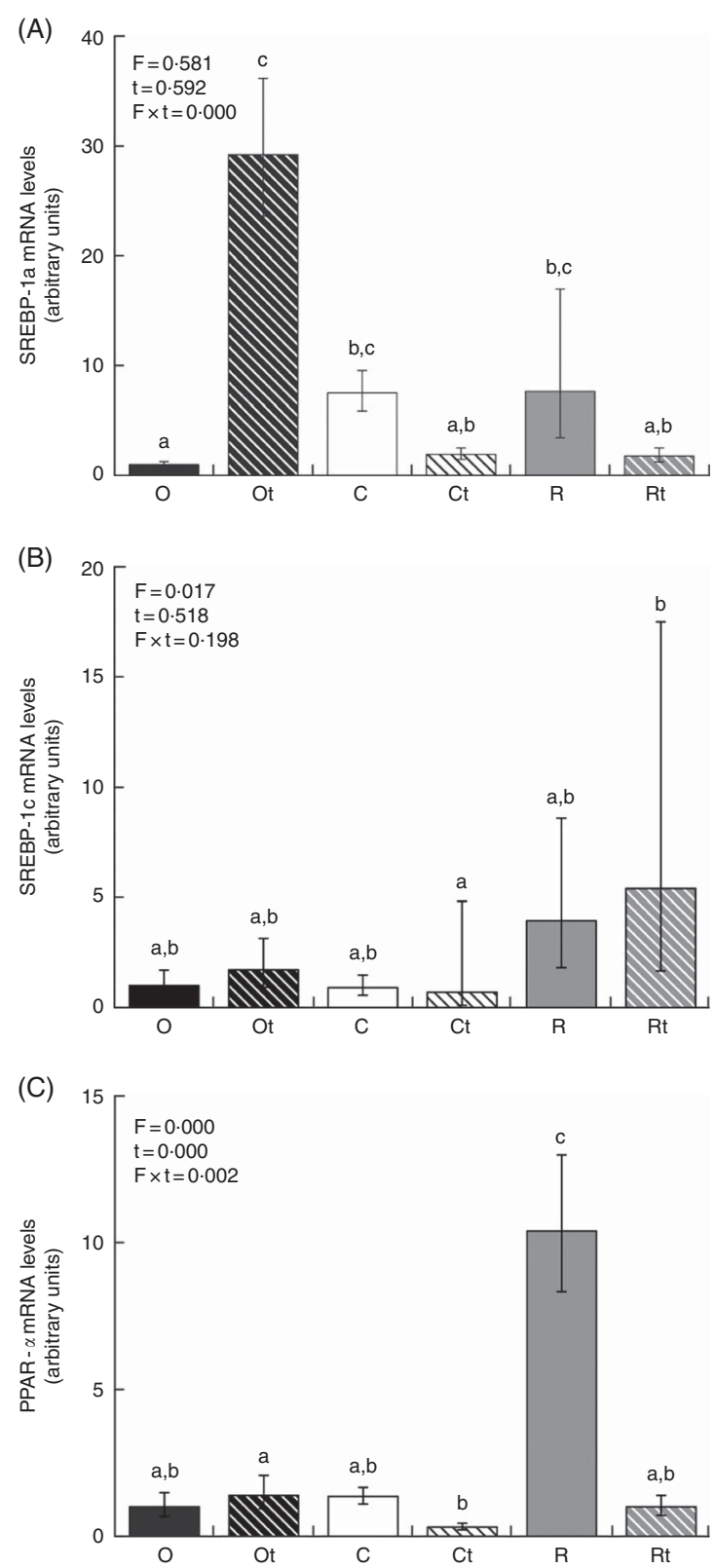

Fig. 2. Liver mRNA levels of transcription factors of key enzymes involved in lipogenesis and $\beta$-oxidation. O, olive oil diet; Ot, olive oil diet supplemented with trans-fatty acids (TFA); $\mathrm{C}$, maize oil diet; $\mathrm{Ct}$, maize oil diet supplemented with TFA; R, rapeseed oil diet; Rt, rapeseed oil diet supplemented with TFA; PPAR-a, peroxisome proliferator-activated receptor; SREBP, sterol regulatory elementbinding protein. Values are means (six animals per group), with their standard errors represented by vertical bars. a,b,c Mean values with unlike letters were significantly different $(P<0.05)$. F, t and $\mathrm{F} \times \mathrm{t}$ correspond to $P$ values of $2 \times 3$ ANOVA to the effect of fat, TFA and interaction of fat $\times$ TFA.

fed diets containing a hydrogenated fat. Nevertheless, the increased LPL activity in EWAT in the Ot and Rt groups $v$. O and $\mathrm{R}$, respectively, is related to the absence of changes in serum TAG despite the enhanced VLDL-TAG secretion rate in those groups.

In addition to EWAT, GM is another tissue with an important contribution to the serum TAG removal ${ }^{(59,60)}$. In the present study, the $\mathrm{R}$ and Rt groups showed lower levels of LPL activity than O and Ot, respectively. Although it has been demonstrated that LPL expression and activity could lead to a muscle TAG accretion ${ }^{(61)}$, 
the mentioned alterations observed in $\mathrm{R} v$. O did not induce changes in GM TAG levels. In animals fed rapeseed oil, the low removal rate induced by EWAT and/or GM might be, at least in part, responsible for the high serum TAG levels. On the other hand, the LPL activity in GM, as well as the muscle TAG levels, did not show any significant alterations in animals fed olive or maize oil. In addition, the low LPL activity induced by TFA in animals fed maize oil was not related to variations in GM TAG levels.

In brief, the effects induced by the partial substitution with TFA to diets containing different edible oils were dependent on the fat source. Hence, the animals fed both Ot and Rt diets showed a higher accretion of liver TAG than their respective controls, and this was associated with an imbalance between lipogenesis and $\beta$-oxidation. However, no differences were observed in liver TAG content between $\mathrm{C}$ and $\mathrm{Ct}$ groups. Specifically, in the Rt group, the increased liver TAG content might be related to a low $\beta$-oxidation, reflected by a decrease in the Ppara expression and Cpt1a expression and activity, whereas in the Ot group the liver TAG accretion was associated with an enhanced lipogenesis. In contrast, TFA did not induce changes in the lipogenesis and $\beta$ oxidation in animals fed maize oil. The high levels of liver TAG in Ot and Rt led to a high secretion rate of VLDL-TAG, suggesting that under our experimental conditions the TFA regulating the hepatic TAG accretion promote the VLDL-TAG secretion. Nevertheless, this effect was not reflected in serum TAG, probably by the compensation through the increased EWAT LPL activity in Ot and Rt. Moreover, the low TAG removal rate by the GM in the R group might be associated with the high serum TAG levels. Summing up, the effects of a diet containing low levels of TFA, with a high proportion of vaccenic acid on liver and serum TAG regulation, depend on the dietary proportions of $n-3, n-6$ and $n-9$ UFA. These results provide insights into some controversial findings associated with the intake of TFA and its effects on human metabolic alterations.

\section{Acknowledgements}

The authors thank Walter DaRú for his technical assistance.

This study was supported by Universidad Nacional del Litoral - Cursos de Acción para la Investigación y el Desarrollo (CAI+D 2011 no. 50120110100165 LI and no. 501201101 00166 LI) - Secretaría de Ciencia y Técnica - UNL.

C. A. B. designed and planned the study, as well as analysed results, interpreted findings and wrote the manuscript; J. S. conducted the study, performed the sample analysis, analysed the data, interpreted findings and prepared the manuscript; M. A. G. contributed to the design and planning of the study, interpreted findings and discussed the manuscript; M. V. S. and J. V. L. carried out collections and analytical determinations and assisted in the maintenance and killing of mice.

The authors have no conflicts of interest to disclose.

\section{References}

1. Abbott SK, Else PL, Atkins TA, et al. (2012) Fatty acid composition of membrane bilayers: importance of diet polyunsaturated fat balance. Biochim Biophys Acta 1818, 1309-1317.
2. Kersten S (2002) Effects of fatty acids on gene expression: role of peroxisome proliferator-activated receptor alpha, liver $\mathrm{X}$ receptor alpha and sterol regulatory element-binding protein-1c. Proc Nutr Soc 61, 371-374.

3. Khan SA \& Vanden Heuvel JP (2003) Role of nuclear receptors in the regulation of gene expression by dietary fatty acids (review). J Nutr Biochem 14, 554-567.

4. Calder PC (2012) Mechanisms of action of (n-3) fatty acids. J Nutr 142, 592S-599S.

5. Simopoulos AP (2002) The importance of the ratio of omega6/omega-3 essential fatty acids. Biomed Pharmacother 56, $365-379$.

6. Jump DB (2011) Fatty acid regulation of hepatic lipid metabolism. Curr Opin Clin Nutr Metab Care 14, 115-120.

7. Misra A, Singhal N \& Khurana L (2010) Obesity, the metabolic syndrome, and type 2 diabetes in developing countries: role of dietary fats and oils. J Am Coll Nutr 29, 289S-301S.

8. Roach C, Feller SE, Ward JA, et al. (2004) Comparison of cis and trans fatty acid containing phosphatidylcholines on membrane properties. Biochemistry 43, 6344-6351.

9. Mozaffarian D, Aro A \& Willett WC (2009) Health effects of trans-fatty acids: experimental and observational evidence. Eur J Clin Nutr 63, Suppl. 2, S5-S21.

10. Voorrips LE, Brants HA, Kardinaal AF, et al. (2002) Intake of conjugated linoleic acid, fat, and other fatty acids in relation to postmenopausal breast cancer: the Netherlands cohort study on diet and cancer. Am J Clin Nutr 76, 873-882.

11. Chavarro JE, Stampfer MJ, Campos H, et al. (2008) A prospective study of trans-fatty acid levels in blood and risk of prostate cancer. Cancer Epidemiol Biomarkers Prev 17, 95-101.

12. Vinikoor LC, Millikan RC, Satia JA, et al. (2010) trans-Fatty acid consumption and its association with distal colorectal cancer in the North Carolina Colon Cancer Study II. Cancer Causes Control 21, 171-180.

13. Clifton PM, Keogh JB \& Noakes M (2004) Trans fatty acids in adipose tissue and the food supply are associated with myocardial infarction. J Nutr 134, 874-879.

14. Moore CE, Alfin-Slater RB \& Aftergood L (1980) Incorporation and disappearance of trans fatty acids in rat tissues. Am J Clin Nutr 33, 2318-2323.

15. Kinsella JE, Bruckner G, Mai J, et al. (1981) Metabolism of trans fatty acids with emphasis on the effects of trans, transoctadecadienoate on lipid composition, essential fatty acid, and prostaglandins: an overview. Am J Clin Nutr 34, 2307-2318.

16. Saín J, González MA, Lavandera JV, et al. (2015) Trans fatty acid retention and conversion rates of fatty acids in tissues depend on dietary fat in mice. Eur J Lipid Sci Tech 117, $1146-1158$.

17. Teegala SM, Willett WC \& Mozaffarian D (2009) Consumption and health effects of trans fatty acids: a review. JAOAC Int $\mathbf{9 2}$, 1250-1257.

18. Wallace SK \& Mozaffarian D (2009) Trans-fatty acids and nonlipid risk factors. Curr Atheroscler Rep 11, 423-433.

19. Bayne K (1996) Revised Guide for the Care and Use of Laboratory Animals available. American Physiological Society. Physiologist 39, 199, 208-111.

20. Reeves PG, Nielsen FH \& Fahey GC Jr (1993) AIN-93 purified diets for laboratory rodents: final report of the American Institute of Nutrition ad hoc writing committee on the reformulation of the AIN-76A rodent diet. J Nutr 123, 1939-1951.

21. Laurell S (1966) A method for routine determination of plasma triglycerides. Scand J Clin Lab Invest 18, 668-672. 
22. Sain J, Gonzalez MA, Lasa A, et al. (2013) Effects of trans-fatty acids on liver lipid metabolism in mice fed on diets showing different fatty acid composition. Ann Nutr Metab 62, 242-249.

23. Lowry OH, Rosebrough NJ, Farr AL, et al. (1951) Protein measurement with the Folin phenol reagent. J Biol Chem $\mathbf{1 9 3}$, 265-275.

24. Bieber LL, Abraham T \& Helmrath T (1972) A rapid spectrophotometric assay for carnitine palmitoyltransferase. Anal Biochem 50, 509-518.

25. Del Prado M, Hernandez-Montes H \& Villalpando S (1994) Characterization of a fluorometric method for lipoprotein lipase. Arch Med Res 25, 331-335.

26. Kramer DN \& Guilbault GG (1963) A substrate for the fluorimetric determination of lipase activity. Anal Chem 35, 588-589.

27. Livak KJ \& Schmittgen TD (2001) Analysis of relative gene expression data using real-time quantitative PCR and the 2(-Delta Delta C(T)) Method. Methods 25, 402-408.

28. Otway S \& Robinson DS (1967) The use of a non-ionic detergent (Triton WR 1339) to determine rates of triglyceride entry into the circulation of the rat under different physiological conditions. J Physiol 190, 321-332.

29. Bernal CA, Basilico MZ, Gutman R, et al. (1989) Secretion and removal rates of very low density lipoprotein triglycerides at the three metabolic periods of hypertriglyceridemia induced by a sucrose rich diet. Nutr Rep Int 40, 71-79.

30. Takeuchi H, Nakamoto T, Mori Y, et al. (2001) Comparative effects of dietary fat types on hepatic enzyme activities related to the synthesis and oxidation of fatty acid and to lipogenesis in rats. Biosci Biotechnol Biochem $\mathbf{6 5}$, 1748-1754.

31. Ferramosca A, Savy V \& Zara V (2008) Olive oil increases the hepatic triacylglycerol content in mice by a distinct influence on the synthesis and oxidation of fatty acids. Biosci Biotechnol Biochem 72, 62-69.

32. Sealls W, Gonzalez M, Brosnan MJ, et al. (2008) Dietary polyunsaturated fatty acids (C18:2 omega6 and C18:3 omega3) do not suppress hepatic lipogenesis. Biochim Biophys Acta 1781, 406-414.

33. Pawar A \& Jump DB (2003) Unsaturated fatty acid regulation of peroxisome proliferator-activated receptor alpha activity in rat primary hepatocytes. J Biol Chem 278, 35931-35939.

34. Giudetti AM, Beynen AC, Lemmens AG, et al. (2003) Hepatic fatty acid metabolism in rats fed diets with different contents of C18:0, C18:1 cis and C18:1 trans isomers. Br J Nutr $\mathbf{9 0}$, 887-893.

35. Sabine JR, McGrath H \& Abraham S (1969) Dietary fat and the inhibition of hepatic lipogenesis in the mouse. J Nutr $\mathbf{9 8}$, 312-318.

36. Musch K, Ojakian MA \& Williams MA (1974) Comparison of alpha-linolenate and oleate in lowering activity of lipogenic enzymes in rat liver: evidence for a greater effect of dietary linoleinate independent of food and carbohydrate intake. Biochim Biophys Acta 337, 343-348.

37. Colandre ME, Diez RS \& Bernal CA (2003) Metabolic effects of trans fatty acids on an experimental dietary model. BrJ Nutr 89, 631-639.

38. Bernal CA, Rovira J, Colandre ME, et al. (2006) Effects of dietary cis and trans unsaturated and saturated fatty acids on the glucose metabolites and enzymes of rats. BrJ Nutr 95, 947-954

39. Dorfman SE, Laurent D, Gounarides JS, et al. (2009) Metabolic implications of dietary trans-fatty acids. Obesity (Silver Spring) 17, 1200-1207.

40. Wang Y, Jacome-Sosa MM, Ruth MR, et al. (2009) Trans-11 vaccenic acid reduces hepatic lipogenesis and chylomicron secretion in JCR:LA-cp rats. J Nutr 139, 2049-2054.
41. Du ZY, Degrace P, Gresti J, et al. (2010) Dissimilar properties of vaccenic versus elaidic acid in beta-oxidation activities and gene regulation in rat liver cells. Lipids 45, 581-591.

42. Meijer GW, van Tol A, van Berkel TJ, et al. (2001) Effect of dietary elaidic versus vaccenic acid on blood and liver lipids in the hamster. Atherosclerosis 157, 31-40.

43. Dashti N, McConathy WJ \& Ontko JA (1980) Production of apolipoproteins E and A-I by rat hepatocytes in primary culture. Biochim Biophys Acta 618, 347-358.

44. Arrol S, Mackness MI \& Durrington PN (2000) The effects of fatty acids on apolipoprotein B secretion by human hepatoma cells (HEP G2). Atherosclerosis 150, 255-264.

45. Dashti N, Feng Q, Freeman MR, et al. (2002) Trans polyunsaturated fatty acids have more adverse effects than saturated fatty acids on the concentration and composition of lipoproteins secreted by human hepatoma HepG 2 cells. J Nutr 132, 2651-2659.

46. Mitmesser SH \& Carr TP (2005) Trans fatty acids alter the lipid composition and size of apoB-100-containing lipoproteins secreted by HepG2 cells. J Nutr Biochem 16, 178-183.

47. Connor SL \& Connor WE (1997) Are fish oils beneficial in the prevention and treatment of coronary artery disease? Am J Clin Nutr 66, 1020S-1031S.

48. Ruiz-Gutierrez V, Perez-Espinosa A, Vazquez CM, et al. (1999) Effects of dietary fats (fish, olive and high-oleic-acid sunflower oils) on lipid composition and antioxidant enzymes in rat liver. Br J Nutr 82, 233-241.

49. Tyburczy C, Major C, Lock AL, et al. (2009) Individual trans octadecenoic acids and partially hydrogenated vegetable oil differentially affect hepatic lipid and lipoprotein metabolism in golden Syrian hamsters. J Nutr 139, 257-263.

50. Michaud SE \& Renier G (2001) Direct regulatory effect of fatty acids on macrophage lipoprotein lipase: potential role of PPARs. Diabetes 50, 660-666.

51. Cryer A, Kirtland J, Jones HM, et al. (1978) Lipoprotein lipase activity in the tissues of guinea pigs exposed to different dietary fats from conception to three months of age. Biochem J 170, 169-172.

52. Murphy MC, Zampelas A, Puddicombe SM, et al. (1993) Pretranslational regulation of the expression of the lipoprotein lipase (EC 3.1.1.34) gene by dietary fatty acids in the rat. $\mathrm{BrJ}$ Nutr 70, 727-736.

53. Baba N, Antoniades K \& Habbal Z (1999) Effects of dietary canola, olive, and linolenic acid enriched olive oils on plasma lipids, lipid peroxidation and lipoprotein lipase activity in rats. Nutr Res 19, 601-612.

54. Baba N, Ghossoub Z \& Habbal Z (2000) Differential effects of dietary oils on plasma lipids, lipid peroxidation and adipose tissue lipoprotein lipase activity in rats. Nutr Res $\mathbf{2 0}$, $1113-1123$

55. Hulsmann WC, Geelhoed-Mieras MM, Jansen H, et al. (1979) Alteration of the lipase activities of muscle, adipose tissue and liver by rapeseed oil feeding of rats. Biochim Biophys Acta 572, 183-187.

56. Pereira-Assumpcao R, Duarte dos Santos F, de Mattos Machado Andrade P, et al. (2004) Effect of variation of transfatty acid in lactating rats' diet on lipoprotein lipase activity in mammary gland, liver, and adipose tissue. Nutrition 20, 806-811.

57. Silva AP, Guimaraes DE, Mizurini DM, et al. (2006) Dietary fatty acids early in life affect lipid metabolism and adiposity in young rats. Lipids $\mathbf{4 1}, 535-541$.

58. Saravanan N, Haseeb A, Ehtesham NZ, et al. (2005) Differential effects of dietary saturated and trans-fatty acids on expression of genes associated with insulin sensitivity in rat adipose tissue. Eur J Endocrinol 153, 159-165. 
59. Goldberg IJ (1996) Lipoprotein lipase and lipolysis: central roles in lipoprotein metabolism and atherogenesis. J Lipid Res 37, 693-707.

60. Olivecrona T, Liu G, Hultin M, et al. (1993) Regulation of lipoprotein lipase. Biochem Soc Trans 21, 509-513.
61. Voshol PJ, Jong MC, Dahlmans VE, et al. (2001) In musclespecific lipoprotein lipase-overexpressing mice, muscle triglyceride content is increased without inhibition of insulinstimulated whole-body and muscle-specific glucose uptake. Diabetes 50, 2585-2590. 